\title{
Online Examination System
}

\author{
Muna R. Hameed ${ }^{1}$, Firas. A. Abdullatif ${ }^{2}$ \\ University of Information Technology and Communication, Baghdad, Iraq ${ }^{1}$ \\ Baghdad University, College of Education for Pure Science/Ibn-Al-Haithem, Baghdad, Iraq ${ }^{2}$
}

\begin{abstract}
Online examination system is a web-based examination system where examinations are given online. either through the internet or intranet using computer system. The main goal of this online examination system is to effectively evaluate the student thoroughly through a totally automated system that not only reduce the required time but also obtain fast and accurate results.
\end{abstract}

Keywords: PHP, web applications, examination systems, database, web server.

\section{INTRODUCTION}

Today ,Online Examination System is considered a fast developing examination method because of its accuracy and speed. It is also needed less manpower to handle the examination. Almost all organizations today, are managing their exams by online examination system, since it reduces student's time in examinations. Organizations can also easily monitor the progress of the student that they give through an examination[1]. As a result of this, the result is calculated in less time. It also helps diminishing the need for paper. Online examination project in PHP is very useful to learn it, According to today's requirement Online examination system is significantly important to the educational institution to prepare the exams, saving the time and effort that is required to check the exam papers and to prepare the results reports. Online examination system helps the educational institutions to monitor their students and keep eyes on their progress. The best use of this system in Scholastic Institute and training centres because it helps in managing the exams and get the results in easy and an efficient manner. Until today the preparing for exams and preparing the results was performed manually, this required more time to complete[2].

\section{LITERATURE SURVEY}

many different researches have focused on the subject of an online examination system these work can be represented as following:

SIETTE: Guzman and Conejo (2005) proposed an online examination system called System of Intelligent Evaluation using Tests for Tele-education (SIETTE). SIETTE is a web-based environment to generate and construct adaptive tests. It can be used for instructional objectives, via combining adaptive student self-assessment test questions with hints and feedback. SIETTE supports secure login and portability features. On the other hand, the other features: resumption capability, multi-instructor,random question selection, random questions distribution and random choices distribution are missing[3].

EMS :Rashad Et. Al. (2010) proposed a web-based online examination system called Exam Management System (EMS). EMS manages the examination and auto-grading for students exams and supports conducting exams, collects the answers, auto mark the submissions, and produce the reports for the test. EMS supports secure login, multi-instructor, and portability features. However, the other features: resumption capability, random question selection, random questions distribution, and random choices distribution are missing[4].

ArvindSingh,NirajShirke,KiranShette 2011:The project evaluates the examiners by using the online examination system concept. The exams will be totally customizable. This system will check results automatically basing on students answers.

CBTS :Fagbola et. al. (2013) developed a Computer Based Test System (CBTS). CBTS is a web-based online examination system developed to address issues such as lack of timing flexibility for automation candidates log-off upon expiration of allowed time, result integrity, guaranty, stand-alone deployment, need for flexibility, robustness, designed to support the examination processes and overcome challenges framing the conduct of examination, auto- marking, auto- submission, and generation report of examination result[3].

\section{III.PROBLEM STATEMENT}

Since the traditional have many drawbacks such as time consuming, Difficulty of analysing the test manually, More observers are required to take exam of many students, Results are not accurate since calculations is done manually, The chance of losing exam's result is higher in current systems, Checking of result is time consuming since it done manually, Limitation of no of student can give examination at a time. with the development of information technology and use it in an orderly and properly helps to overcome the existing error in the manual system . Online examination system saves the exams information in a database, and this make it an easier way to give exam teachers can add theirs exams rules, and student can give exam in a totally automated system[5].

\section{IV.THE PROPOSED SYSTEM}

online examination system save the exams information in a database, teachers can add/delete questions, set the correct 
answers, specify the exam period, register students ,delete ii.

Deleting Questions: include deleting questions of students, show questions for students randomly, calculate the three types of questions (true/false, multiple choices, and show the final results for students. image matching).

\section{A. System design}

The online examination system uses client/ server architecture. At the client by using a web browser can connect via internet or local host with the server where PHP and MySQL in the server side are responsible for the preparing exams processes and save and return data from database.

Figure 1 represent an overview of online examination system

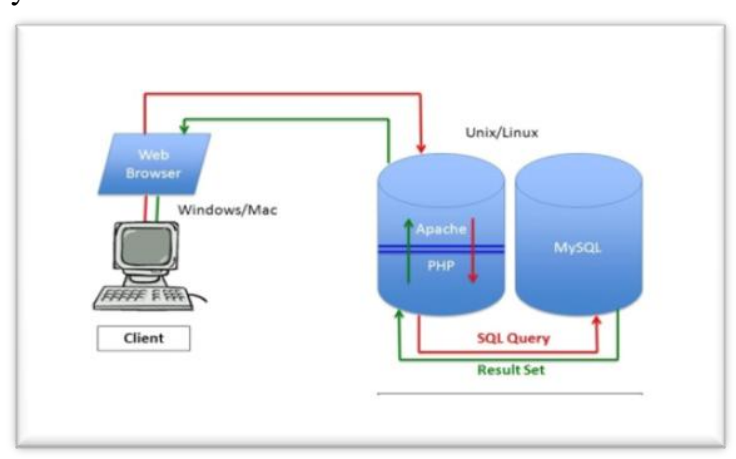

Figure 1 system overview design

\section{B. System activities}

1. Login system

Login system contain the following programs

- $\quad \operatorname{login}$ as admin

By using already stored admin name and password the individual can log on to the system any time he/she desires as an admin to manage the admin activities. Logging is successful only if the input detail is matched with the database, else an error message is displayed.

\section{- $\quad$ Login as student}

The information of each student will be sorted by the admin upon the registration process, enabling this way the particular student to $\log$ on the system without having to undergo the process of registration again. Logging is successful only if the input detail is matched with the database, else an error message is displayed.

\section{Admin activities}

Admin activities contain the following programs:

\section{- Questions management}

Managing questions contain two main operations:

i. $\quad$ Adding Questions: include adding three type of The general specification of the online examination system questions according to the admin desires either (true/false, (OES) can be explained in figure 3 multiple choices, image matching).
- $\quad$ Students management

Managing students contain two main operations:

i. Registering students: include inserting the information of each student (student name, email, and password) to complete the registration process.

ii. Deleting student: by inserting the (name and email) of the student to be deleted the admin can delete any student.

- Result management: show all students results.

3. Students activities

Student activities contain the following operations:

- $\quad$ Give the exam:

After the student logging in, a group of questions will be displayed to him to start and give an exam.

- $\quad$ Get the results:

After answering all the questions in a specified period the student will finish the exam and his/her degree will be displayed on the screen.

\section{Database design}

In order to fully use MySQL server technology, it is essential to make sure that the database is well designed. The files names chosen to label all the tables created within the database attempt to reflect the table's purpose and, therefore, contribute to well-design system. The intimal step in designing was to decide, according to the requirements and specifications of the project, which tables should be created, and what type of information each one should hold. The final design had taken from as explained in figure(2).

\begin{tabular}{|l|r|l|l|l|r|}
\hline Table & Rows & Type & Collation & Size & Overhead \\
\hline admin_selcter & 1 & InnoDB & utf8_general_ci & $16 \mathrm{KiB}$ & - \\
\hline admnlgin & 1 & InnoDB & latin1_swedish_ci & $16 \mathrm{KiB}$ & - \\
\hline arich & 2,632 & InnoDB & utf8_general_ci & $144 \mathrm{KiB}$ & - \\
\hline imageadd & 14 & InnoDB & latin1_swedish_ci & $2.5 \mathrm{MiB}$ & - \\
\hline mcq & 16 & InnoDB & latin1_swedish_ci & $16 \mathrm{KiB}$ & - \\
\hline result & 0 & InnoDB & latin1_swedish_ci & $16 \mathrm{KiB}$ & - \\
\hline std & 4 & InnoDB & latin1_swedish_ci & $16 \mathrm{KiB}$ & - \\
\hline trfa & 16 & InnoDB & latin1_swedish_ci & $16 \mathrm{KiB}$ & - \\
\hline $\mathbf{8}$ tables & $\mathbf{2 , 6 8 4}$ & InnoDB & latin1_swedish_ci & $\mathbf{2 . 8} \mathrm{MiB}$ & O B \\
\hline
\end{tabular}

Figure 2 database table

\section{System Implementation}




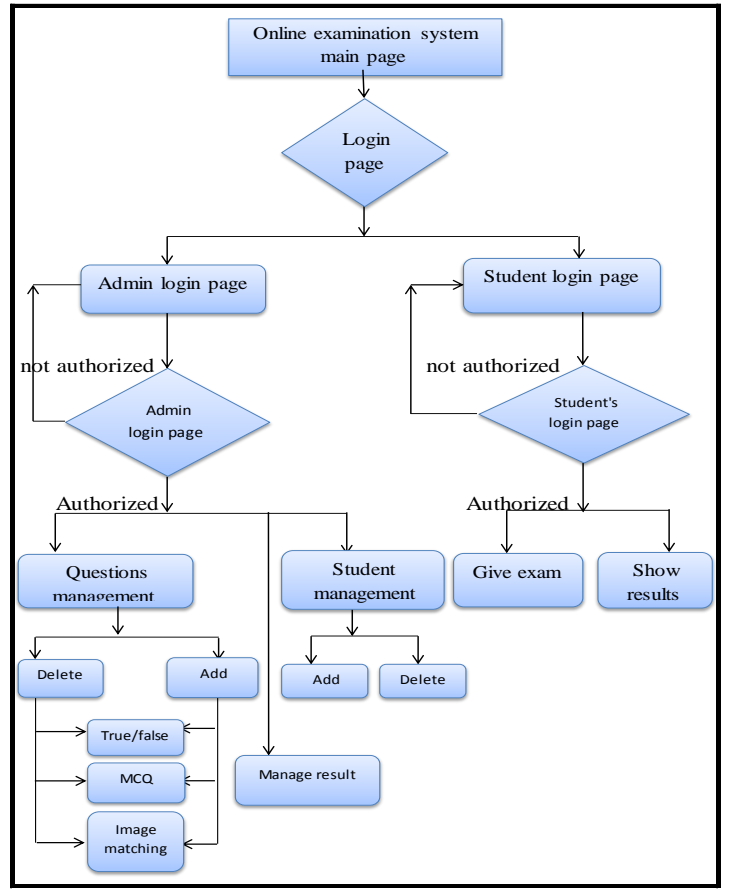

Figure 3 general diagram

\section{E. System interface}

The system allow users to login in two ways either as an admin or student, as shown in figure 4

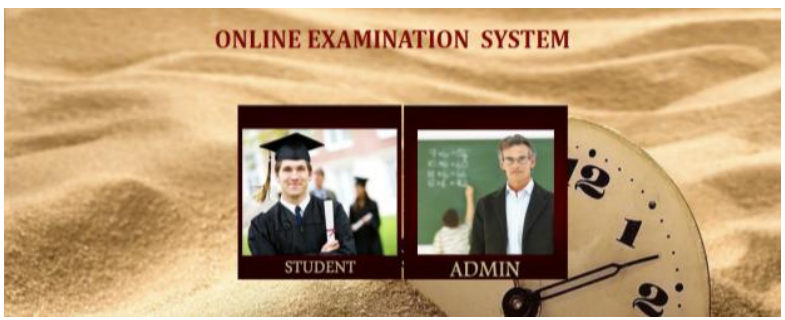

Figure 4 main page

1- As admin: when the user choose to login as an admin the main page will lead him to the admin login page, which will ask for user name and password.as shown in figure(5)

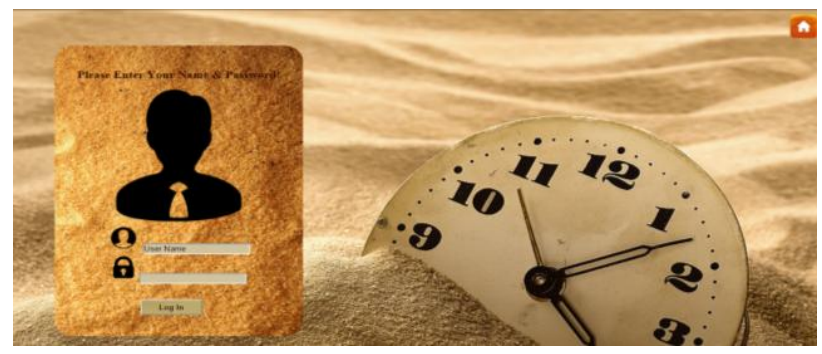

Figure 5 Admin Login Page

After checking for the correct user name and password the system will lead the admin to the dashboard page as shown in figure 6

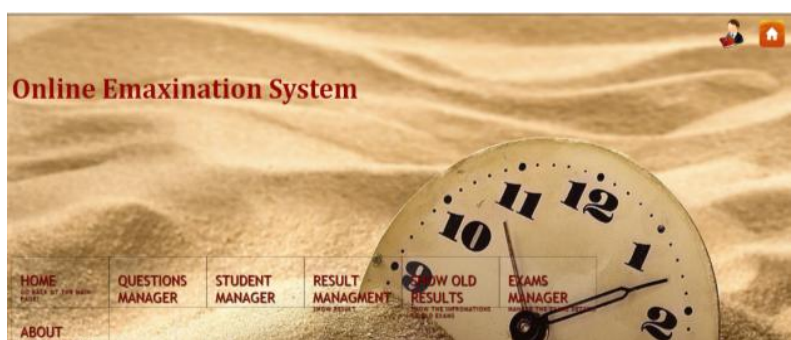

Figure 6 dashboard page

The questions management page gives the admin the ability to add three types of questions as shown in figure 7 Adding the true/false question page for example

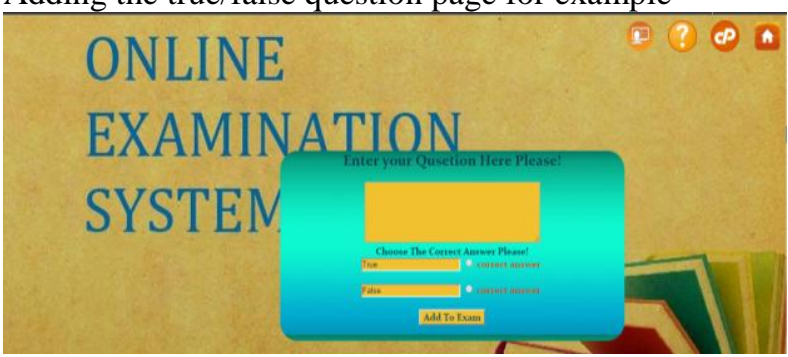

Figure 7 Questions Addition

The questions management page gives the admin the ability to delete three types of questions .The deletion page of True/false question for example

as shown in figure 8

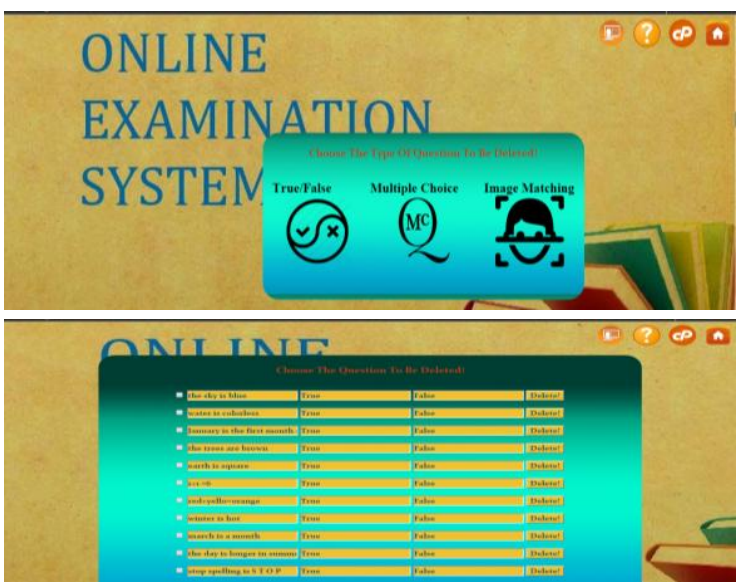

Figure 8 Questions Deletion

The students management page shown in figure 9 gives the admin ability to add/delete student

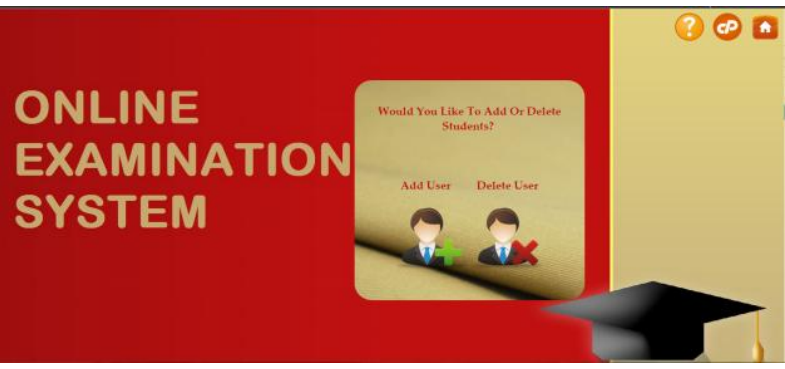




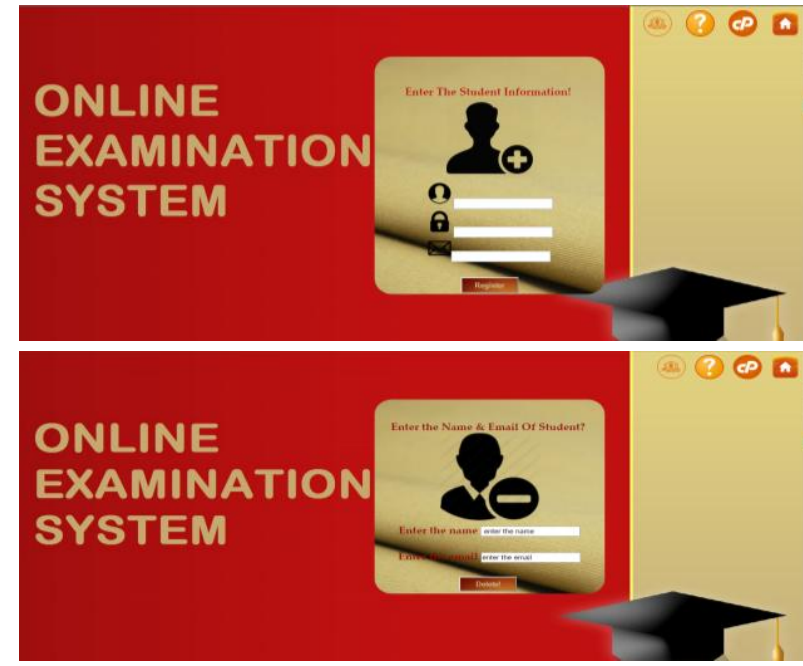

Figure 9 student management

The dashboard page also allows the admin to show the results of the older exams through the managing exams page(this page shows the results of older exams that had been taken at previous time), This page allows admin to display the previous exam's results that have been stored each time a student give an exam as shown in figure10

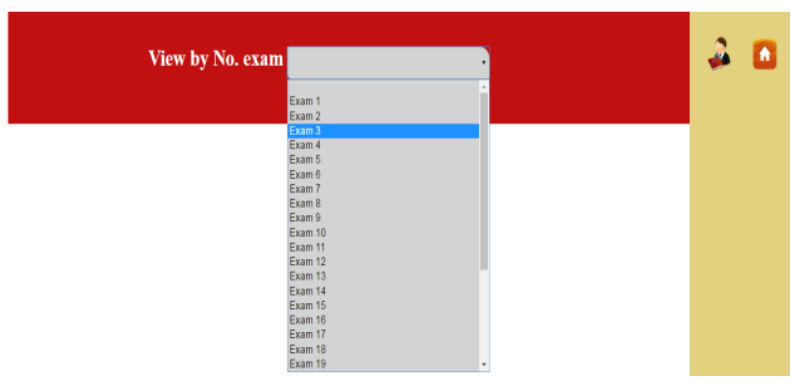

Figure 10 Show Old Results

The information of a particular exam will be displayed to the admin by choosing this exam (e.g. let's say we choose Exam 3 the system will display the exam's information of each students had exam for three times).

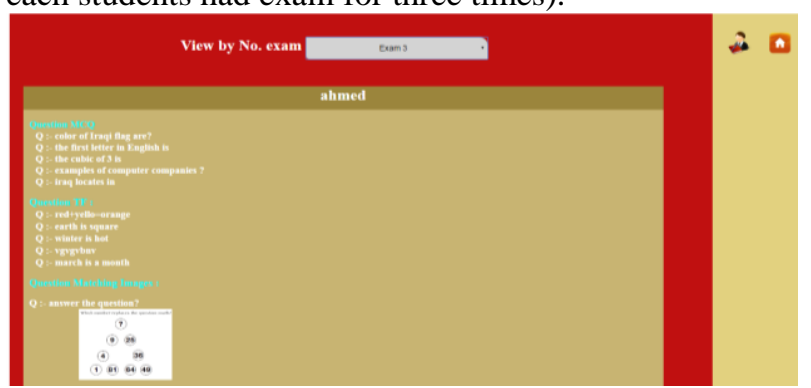

Figure 11 Shows Previous Exams Information

The dashboard page also enable admin to manage the exams through the managing exams page as shown in figure 12

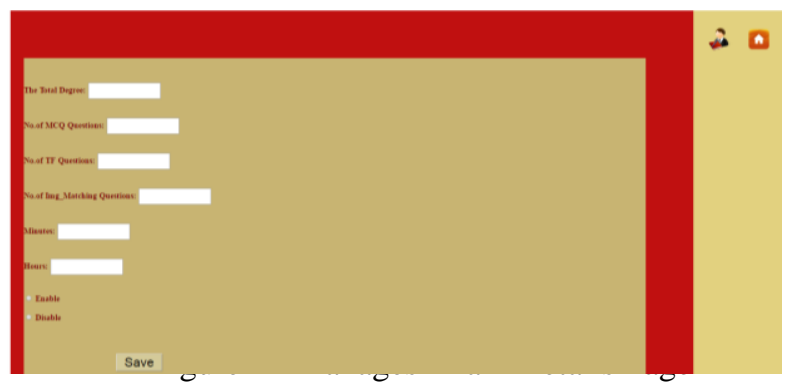

2- As student :When the user login as a student, he/she will be represented with student login page as shown in figure 13

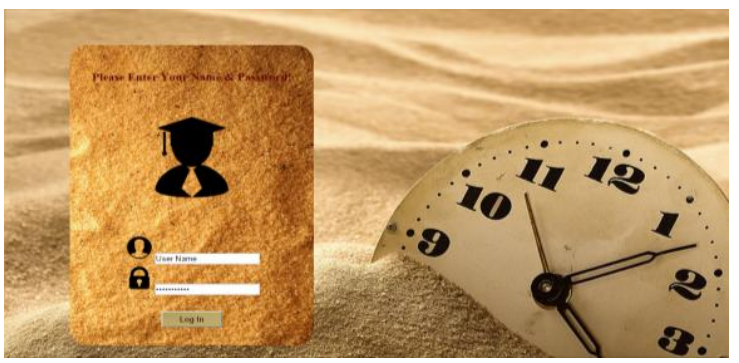

Figure 13 student Login Page

After authentication the student will be represented with the quiz page(which contains the questions set by the admin , and the time allowed for the exam and the current exam ) as shown in figure 14

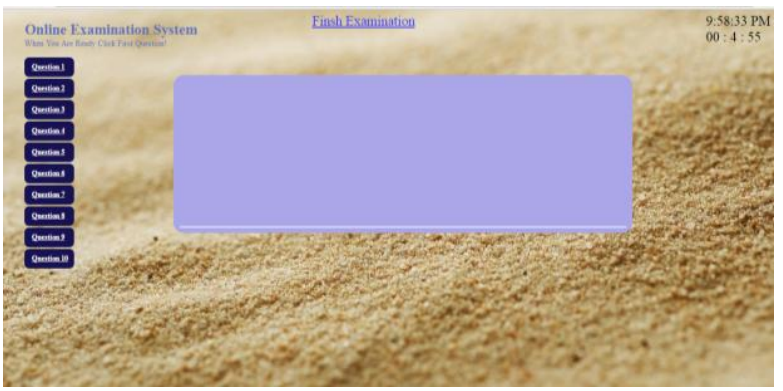

Figure 14 Exam Page

After answering the questions and clicking the finish exam button or by the end of allowed time the result page will be displayed as shown in figure 15

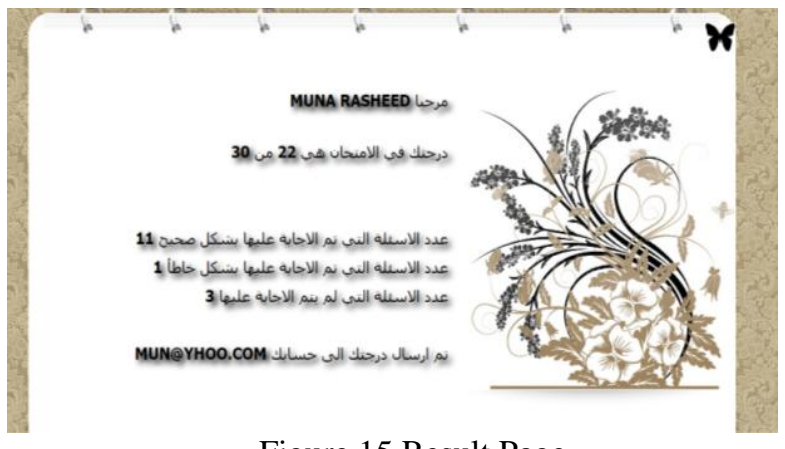

Figure 15 Result Page 


\section{Conclusion}

Using an open source language gives us more flexibility, but at the same time it required more time to be programmed.The proposed Online Examination System (OES) can be easily adopted by universities and institutions in order to make the exam more secure and more flexible.The system is subdivided into two main subsystems (student and administrator) that are designed to give the system maximum benefit by demonstrating carefully each subsystem service.The administrator's functions are clearly identified to be able to manipulate user's information such as add (register), delete users and managing the exam materials and content such as add, delete questions, Thus the proposed system is easy and flexible because for future maintenance and development because each subsystem can be handled separately without influence on other system.

\section{ACKNOWLEDGMENT}

First of all, praise be Allah for his guidance that enabled me to complete this project.I would like to express my appreciations to my supervisor FirasA.Abdullatif for his guidance and advice that he gave to me throughout the progress of this project and thanks for all those who encourage me and support me, family, friends.

\section{REFERENCES}

[1] SWeaver, D., et al. (2005). Evaluation: WebCT and the student experience. Evaluations and Assessment Conference.

[2] Tate, L. (2002). "Using the interactive whiteboard to increase student retention, attention, participation, interest, and success in a required general education college course." Retrieved January 30: 2007.

[3] Tallent-Runnels, M. K., et al. (2006). "Teaching courses online: A review of the research." Review of educational research 76(1): 93135.

[4] Downing, D., et al. (2000). Dictionary of computer and Internet terms, Barron's Educational series.

[5] Ainscough, T. L. (1996). "The Internet for the rest of us: marketing on the World Wide Web." Journal of consumer marketing 13(2): 3647. 